\title{
Liderança em ambientes de cuidados críticos: reflexões e desafios à Enfermagem Brasileira
}

\author{
Leadership in critical care settings: reflections and challenges for the Brazilian Nursing \\ Liderazgo en ambientes intensivos de atención: reflexiones y desafíos para la Enfermería Brasileña
}

\author{
Francine Lima Gelbcke', Lúcia Amante de Souzal, \\ Grace M. Dal Sasso', Eliane Nascimento', Maria Bettina Camargo Bulb' \\ 'Universidade Federal de Santa Catarina. Departamento de Enfermagem. Florianópolis, SC
}

Submissão: 15/03/2008

Aprovação: 24/1 1/2008

\section{RESUMO}

O objetivo deste estudo foi refletir sobre a liderança, em especial da enfermagem em cuidados intensivos, com base na perspectiva de enfermeiros, docentes de enfermagem, acadêmicos e na literatura sobre o tema. A liderança da enfermeira' de unidades de cuidados críticos enfrenta desafios e paradoxos e está presente no planejamento do cuidado, nos momentos dos conflitos éticos e bioéticos, na supervisão dos cuidados, na capacidade de tomar decisões com rapidez e segurança, no saber lidar com as Questões Que envolvem o processo de viver e morrer.

Descritores: Enfermagem; Liderança; Unidades de terapia intensiva.

\begin{abstract}
The objective of this study was to reflect on the leadership, especially in the intensive care nursing, based on the prospect of nurses, teachers, nursing students and in the literature on the subject. The leadership of the nurse in intensive care units faces challenges and paradoxes and is present in the planning of care, in the moments of ethical and bioethical conflicts, in the supervision of care, in capacity of making decisions Quickly and safety, in knowing deal with the issues involving the process of living and dying.
\end{abstract}

Descriptors: Nursing; Leadership; Intensive care units.

\section{RESUMEN}

El objetivo del estudió fui reflexionar acerca del liderazgo, en especial de la enfermería en cuidados intensivos, con base en la perspectiva de enfermeros, docentes de enfermería, estudiantes y en la literatura acerca del tema. Lo liderazgo de la enfermera de unidades de cuidados intensivos enfrenta desafíos y paradojas y esta presente en lo planeamiento de lo cuidado, en los momentos de los conflictos éticos y bioéticos, en la supervisión de los cuidados, en la capacidad de tomar decisiones con rapidez y seguridad, en lo saber tratar con las cuestiones Que envolvían lo proceso de vivir y morir.

Descriptores: Enfermería; Liderazgo; Unidades de terapia intensiva. 


\section{CONSIDERAÇÕES INICIAIS}

O tema liderança é extremamente pertinente, haja vista o cenário de incertezas Que afeta a sociedade contemporânea e conseQüentemente as organizações hospitalares e os serviços de enfermagem no Que diz respeito à sua administração, pois estas instituições, como as demais empresas, enfrentam instabilidades políticas, sociais, econômicas, como também tecnológicas, colocando as instituições hospitalares em crise, especialmente no Brasil $^{(1)}$. A enfermeira é uma profissional Que precisa organizar o trabalho de forma que cada integrante da equipe de enfermagem contribua com eficiência e competência no atendimento das pessoas Que procuram o serviço, especialmente Quando este serviço é de cuidados críticos, onde são comuns situações Que exigem observações e decisões rápidas e seguras, cuidado freeüente e prolongado, Que envolve uma seeüência de procedimentos invasivos e complexos, mediados pela tecnologia.

Diante da complexidade do tema surgem as seguintes indagações: Qual a importância da liderança da enfermagem em uma unidade de cuidados intensivos? Em Que situações esta liderança se expressa? Que características a enfermeira deve ter para ser líder da equipe? Quão preparadas estão as futuras líderes da enfermagem de cuidados críticos? Para responder a estes Questionamentos traçou-se como objetivo refletir sobre liderança da enfermagem em ambientes de cuidados críticos. Para desenvolver este estudo descritivo - reflexivo buscou-se nos meses de outubro e novembro de 2007 conhecer a percepção sobre liderança da enfermagem, de enfermeiras Que atuam em unidades de tratamento intensivo adulto e neonatal, de professoras Que ministram a disciplina Cuidado de Enfermagem ao Individuo Adulto em Condição Crítica de Saúde do Curso de Graduação em Enfermagem da Universidade Federal de Santa Catarina e de acadêmicas que atuaram nestas unidades no último estágio do referido curso, além da consulta a bibliografias sobre o tema. Dois eixos sustentam a reflexão, Quais sejam a liderança como parte do processo de trabalho da enfermeira e a liderança no contexto do trabalho em unidades críticas.

\section{LIDERANÇA EM AMBIENTES CRÍTICOS}

Liderança como parte do processo de trabalho da enfermeira

No processo de trabalho a enfermeira desenvolve ações de cuidado, de gerenciamento, de pesøuisa e educação, Que possuem objetivos específicos, de acordo com cada processo particular, visando, de uma maneira geral, o bem-estar do ser humano. Reconhece-se Que o cuidado do ser humano em sua complexidade tem sido apontado como objeto epistemológico da enfermagem, por diversos autores ${ }^{(2)}$. O cuidado terapêutico é uma ação Que se desenvolve e termina na e com a pessoa, carregado de valor (ético e estético), sendo um bem necessário às pessoas ${ }^{(3)}$.

E eis então Que emerge um grande desafio: liderar a equipe no sentido de Que este cuidado seja efetivamente terapêutico e executado com o compromisso de todos. Destaca-se que a formação da enfermeira privilegia o cuidado direto, a educação e o gerenciamento da assistência, no entanto, o mercado de trabalho espera Que a enfermeira realize o controle burocrático da instituição. Há, portanto, um descompasso no fazer da enfermeira, Que precisaf ser discutido, visando encontrar alternativas Que atendam o desenvolvimento desses papéis instituídos: cuidar, gerenciar, pesquisar e educar ${ }^{(4,5)}$.

No espaço assistencial, principalmente no hospitalar, é a enfermeira Que articula diferentes serviços, realizando a coordenação do cuidado, desempenhando um papel silencioso no cotidiano de trabalho, visando garantir os insumos necessários ao cuidado $^{(6)}$. Assumir o cuidado significa ter responsabilidade de articular os diferentes profissionais, em um trabalho em equipe, interdisciplinar, horizontal, de colaboração, visando o sujeito do cuidado em sua integralidade bio-psico-social, com necessidades a serem atendidas, mas também com desejos, emoções, com objetividade e subjetividade.

\section{Liderança e sua importância no contexto do trabalho em unidades críticas}

A liderança se torna uma tarefa cada vez mais árdua- em função da exigência de melhores resultados, da inovação e crescimento constantes, sendo uma ferramenta imprescindível no processo de trabalho da enfermeira. Um estudo fenomenológico com o intuito de explorar como os indivíduos experenciavam a liderança, apontou a importância da presença do líder no seu trabalho diário para prestar um cuidado de Qualidade ao paciente, cujos participantes descreveram o distanciamento das líderes em enfermagem como um obstáculo ao crescimento da equipe e a melhoria do cuidado ao paciente ${ }^{(7)}$.

Dentre as várias definições de liderança concorda-se Que a "liderança é um processo grupal, onde ocorre uma influência com a finalidade de alcançar uma meta; portanto, está ligada a um sentido de ação, um senso de movimento, passível de ser aprendida $^{(8)}$ e, neste sentido, a enfermeira deve estar preparada para um novo agir, desenvolvendo e amadurecendo um novo tipo de liderança, mudando o perfil de burocrata para coordenadora do cuidado, sendo motivadora e integrada às ações das pessoas e da equipe ${ }^{(6,9)}$.

Quando se discute a importância da liderança da enfermagem em ambientes de cuidados críticos, estas Questões do líder como motivador do grupo estiveram presentes, tanto nos depoimentos das enfermeiras, como das professoras. Para tanto, liderar é saber conduzir, organizando o trabalho da equipe, visando um atendimento eficiente, pois o líder é o ponto de apoio para a equipe, Quer na educação ou na coordenação do serviço, estimulando a equipe para desenvolver plenamente seu potencial, o que interferirá diretamente na Qualidade da assistência.

Evidenciou-se ainda a importância da enfermeira enQuanto coordenadora da equipe, principalmente em situações críticas, Que exigem a tomada de decisão rápida. A enfermeira é a articuladora, sendo reconhecida em função do seu saber, de sua competência, Que influencia o seu fazer e o próprio reconhecimento e credibilidade da equipe. Tem um papel de destaque nas situações de urgência e emergência, Que exigem escolhas rápidas, sendo assim, a importância da liderança para a enfermeira de uma UTI reside na utilização do conhecimento teórico, filosófico e científico Que possibilita escolhas técnicas sustentadas pela ética e bioética. Neste contexto, ela utiliza uma abordagem multifacetada incorporando bases técnicas, emocionais, gerenciais, psicossociais, além de habilidades cognitivas e de liderança. Ao mesmo tempo é 
um trabalho fundamental poreue concilia os resultados e as adversidades do cuidado ao paciente ao ambiente efetivo de prática $^{(10)}$

Considerando a UTI como um ambiente em Que estão presentes: vida e morte; humanidade e tecnologia; objetivo e subjetivo; a liderança da enfermagem acaba transparecendo mais, principalmente frente ao risco iminente de morte. E, neste sentido, acredita-se Que a utilização dos equipamentos de ponta, deve ser permeada pela escuta sensível, acolhimento, cuidado, olhar ao outro, superando o-mito da UTI como local de morte. Para viabilizar a integralidade do cuidado há Que se estabelecer mudanças no cotidiano das instituições de saúde, buscando-se a responsabilização no cuidado ao paciente, estabelecendo-se um vínculo e um cuidado Que tenha como princípio as necessidades singulares dos sujeitos.

O trabalho interdisciplinar depende do compartilhar saberes e poderes, sendo necessário flexibilizar as relações, convivendo de forma mais harmônica com as diferentes especialidades, entendendo a complementaridade do cuidado e garantindo-se a autonomia profissional. Desta forma, a liderança se manifesta em diferentes momentos, entre os Quais, como afirma uma das acadêmicas: "Nas decisões junto à equipe interdisciplinar na condução clínica do paciente, através de planos de cuidados de enfermagem...". Portanto, as principais características e comportamentos de um líder na prática clínica envolvem dedicação, entusiasmo, otimismo, comportamento profissional, abertura a idéias, habilidades visionárias, habilidade para priorizar, focalizar os objetivos e comprometimento com a aprendizagem e a pesquisa ${ }^{(10)}$.

Outro fator Que interfere na liderança da enfermeira é a comunicação, já Que está na base das práticas de liderança, pois permite a essa "profissional o desempenho de suas ações através de inter-relações com o cliente, a instituição, a equipe médica e o pessoal de enfermagem, buscando a melhoria da Qualidade da assistência prestada"(11). A liderança e a comunicação se fazem necessárias, em função de diferentes conflitos Que precisam ser administrados, Quer internamente na equipe, Quer com os demais profissionais. Este é um dos desafios colocados pelas profissionais e na própria literatura

Em uma unidade de cuidados críticos, em Que o trabalho ocorre em um ambiente restrito, tenso e estressante, superar as diferenças e os conflitos é algo extremamente necessário. E é na equipe de enfermagem Que se tem um espaço para construir novos laços e relações, em Que compartilhar seja uma premissa, em Que o respeito à diversidade esteja presente, em Que a comunicação seja um instrumento e não um entrave, em Que se construam relações mais harmônicas e democráticas, embora se reconheça Que os são necessários para impulsionar mudanças e assim devem ser trabalhados. A liderança da enfermagem se expressa, portanto, em diferentes aspectos: nas situações críticas Que envolvem a tomada de decisão, na resolução de conflitos, na articulação com outros profissionais visando a interdisciplinaridade, na comunicação e nas relações interpessoais com equipe de enfermagem, equipe de saúde e pacientes/famíliares.

Por outro lado, a liderança está presente também no planejamento do cuidado, nos momentos de conflitos ético e bioéticos e de advogar em favor do paciente, na monitorização de indicadores de avaliação de desempenho e de Qualidade na unidade, na supervisão dos cuidados, na interação com familiares e equipe multiprofissional, na administração da unidade, entre outros. E para dar conta de todas estas competências, alguns atributos são necessários e foram destacados pelas enfermeiras, professoras e acadêmicas: ser humanitário, saber reconhecer os limites do outro e as necessidades pessoais e profissionais, ser responsabilidade, ser ética, hábil e competente. Além disto é preciso ter um bom relacionamento com o grupo, ser uma pessoa neutra, ativa, Que articule assistência e gerenciamento, estar disponível, ter capacidade de tomar decisões e saber trabalhar em equipe, ser segura, hábil, rápida e decidida Quando necessário, ao mesmo tempo calma e tolerante Quando apropriado. É importante também ser compreensiva, uma vez Que a experiência em UTI é traumática para pacientes, familiares e o trabalho da equipe é desgastante por si só. Ser líder implica, ainda, ser um facilitador e regente da equipe, compreender claramente as competências e habilidades essenciais da profissão, distribuir poder.

Estes atributos apontados também aparecem na literatura, dando credibilidade ao líder, principalmente no Que concerne aos aspectos de comunicação, honestidade, integridade, determinação e responsabilidade $^{(9,12,13)}$. Para ser líder, em uma unidade de cuidados críticos, há Que se ter conhecimento, ser agregador, utilizar-se da comunicação como uma ferramenta para o exercício da liderança, pautar-se na ética, respeitar o outro em sua individualidade, sendo humano e trabalhar as Questões interpessoais, estimulando a equipe, motivando-a a um cuidado sensível e terapêutico. Ainda, o papel de líder em unidades críticas, exige clareza de pensamento sobre a natureza exata da contribuição da enfermagem nos ambientes de cuidados críticos. ReQuer avaliação da evidência estabelecida para apoiar esta prática de cuidado, reQuer a liderança na segurança do paciente. Finalmente, exige a capacidade de crítica e, de objetivamente saber afirmá-la utilizando suas próprias habilidades de argumentação e impacto ${ }^{(14)}$.

Mas estas são características presentes apenas nos líderes das unidades críticas? O Que difere a liderança da enfermagem em uma unidade de cuidados críticos das demais unidades? Entendese Que o exercício da liderança, bem como as características ressaltadas neste estudo são pertinentes em QualQuer ambiente de cuidados em saúde, especialmente porQue a liderança não reQuer um tipo específico de personalidade ou um treinamento formal. Sobretudo, porque os líderes de sucesso freqüentemente alcançam êxito nos seus objetivos por galgar passos pequenos e firmes, cuidadosos e eficientes, ponderados e assertivos, para influenciar outras pessoas a atingir um determinado objetivo e advogar em favor do paciente ${ }^{(15)}$.

\section{CONSIDERAÇÕES FINAIS}

Possivelmente, a principal diferença da liderança em uma unidade de cuidados críticos seja o desafio em integrar o cuidado complexo de pacientes graves e de risco a um ambiente seguro, harmônico e científico alicerçado não apenas na objetividade, mas também na subjetividade, na Qual o sujeito do cuidado esteja no centro das atenções, no sentido de manutenção da vida e também como uma pessoa Que tem medos, sensações, emoções e seja compreendido como integral único e indivisível, um sujeito cidadão. Acredita-se Que a liderança vai se constituindo ao longo da trajetória do 
profissional e deve estar a serviço da mudança efetiva, alicerçada na justiça, na liberdade, na busca da autonomia, na responsabilidade, Que pode "elevar os trabalhadores de enfermagem à condição de construtores de seu tempo, sua história e sua vida"(12).

\section{REFERÊNCIAS}

1. Higa E, Trevisan MA. Os estilos de liderança idealizados pelos enfermeiros. Rev Latino-am Enfermagem 2005; 13(1): 5964.

2. Leopardi MT, Gelbcke FL, Ramos FRS. Cuidado: objeto de trabalho ou objeto epistemológico da enfermagem? Texto Contexto Enferm 2001;10 (1): 32-49.

3. Reibnitz KS, Prado ML. Formação do Profissional críticocriativo: a investigação como atitude de (re)conhecimento do mundo. Texto Contexto Enferm 2003; 12(1): 26-33.

4. Santos I, Oliveira S, Castro C. Gerência do processo de trabalho em enfermagem: liderança da enfermeira em unidades hospitalares. Texto Contexto Enferm 2006; 15(3): 393-400.

5. Crestani MM, Pinheiro GC, Rosseto AP, Nascimento ERP. Refletindo o assistir $x$ administrar em enfermagem: uma visão de acadêmicas. Conhecer Enfermagem 2004; 1/2(1/2): 2932.

6. Cecílio L, Merhy EE. A integralidade do cuidado como eixo da gestão hospitalar. Campinas; 2003. [citado em 25 jun 2006]. Disponível em: http:www.hc.ufmg.br/gids/Integralidade.doc

7. Rosengren K, Athlin E, Segesten K. Presence and availability; staff conceptions of nursing leadership in an intensive care unit. I Nurs Manag 2007; 15: 522-9.
8. Lourenço MR, Trevizan MA. Líderes da enfermagem brasileira - sua visão sobre a temática da liderança e sua percepção a respeito da relação liderança \& enfermagem. Rev Latino-am Enfermagem 2001; 9(3): 14-9.

9. Simões AL, Favaro N. O desafio da liderança para o enfermeiro. Rev Latino-am Enfermagem 2003; I I (5): 567-73.

10. Pintar KA, Capuano TA, Rosser GD. Developing Clinical Leadership Capability. I Continuing Educ Nurs 2007; 38(3): 115-21.

11. Spagnuolo RS, Pereira MLT. Práticas de saúde em enfermagem e comunicação: um estudo de revisão de literatura. Ciência Saúde Coletiva 2007; 12(6): 1306-10.

12. Rozendo C, Gomes E. Liderança na enfermagem brasileira: aproximando-se de sua desmistificação. Rev Latino-am Enfermagem 1998; 6(5): 67-78.

13. Benito G, Becker L. Atitudes gerenciais do enfermeiro no Programa Saúde da Família. Rev Bras Enferm 2007; 60(3): 312-6.

14. Coombs M. Managing today's reality of delivering critical care nursing [editorial]. Critical Care Nurs 2006; I I (5): 2 16-7.

15. Beyea S. Being a patient safety leader. AORNI 2008; 87(1): $22 \mathrm{I}-3$. 